\title{
Department of International Relations of CONICYT
}

International cooperation is a central component in the development of science, technology and innovation in general. Although from the beginning collaborative work has been an inherent factor in high level research, it becomes imperative if one is to meet the increasing challenges of a globalized society. Together with allowing the exchange of knowledge and experiences, international cooperation constitutes a key instrument that helps processes of sustainable development and integration between countries. Not only does it allow cross learning, but it makes the reduction of breaches in knowledge and competences faster and more effective. At present, benefits of international cooperation go beyond the mere leverage of resources, contributing to multidisciplinary work and to the shared handling of risks, among other key points. With international cooperation it is possible to think about how to make a real contribution to the quality and compatibility of world science, so that it may become efficacious towards improving the quality of life of citizens.

At the local level, the National Commission of Scientific and Technological Research, CONICYT, is committed to supporting two strategic targets: the promotion of advanced human capital formation and the development and strengthening of the scientific and technological base.

In this framework, the Department of International Relations (DRI) has undertaken the mission to encourage the establishment and improvement of international links between the national scientific community and foreign partners, through the implementation of an international cooperation policy integrated into the different departments of the institution.
Several instruments are available to move this mission forward. Historically, a fundamental instrument has been financing of researchers exchange with foreign counterparts, mainly in order to support mobility in the frame of collaborative and complementary investigations. One of the main programs towards this end has been the promotion of the incorporation of graduate students and postdoctoral fellows to such mobility projects. This strategy therefore puts together the exchange of scientific information, different joint scholarship programs, funding of collaborative investigation and incorporation to networks of excellence, among others.

In this context, the promotion of workshops (also known as the workshop instrument) occupies a place of critical importance. Workshops allow assembling actors of diverse ambiences around a central topic. This way, a fruitful exchange is generated between participants, who generally organize themselves in workgroups, favoring both the content updates as well as the emergence of novel questions that can motivate new lines of work. The incorporation of young investigators to this activity increases the potential to generate agreements and lines for future joint research. For this instrument to fulfill the abovementioned objectives clear targets and continuity are needed in time.

For the DRI, articulation workshops -as this general initiative is called-represent a unique opportunity that is put at the disposal of the national scientific community. It has demonstrated its effectiveness in supporting the continuity and development of international relationship established by national experts, reinforcing bonds and generating new 
networks. Furthermore, the active involvement of the local community in these initiatives shows that the potentiality and interest is recognized and valued. Indeed, as a result of these workshops, the building of new activities of exchange and the generation of joint proposals is facilitated and happens naturally, an outcome that explicitly corresponds to one of the main aspects of the departmental mission.

\section{XAVIER ALTAMIRANO}

Director

Departamento de Relaciones Internacionales (DRI) - CONICYT

\section{CECILIA VELIT}

Coordinadora Programa UE/Francia Departamento de Relaciones Internacionales (DRI) - CONICYT 